Vol. 10 (4): 609-616 (2020)

\title{
A STUDY ON DIFFERENCES OF ALBANIAN Salvia officinalis L. ESSENTIAL OILS DEPENDING ON GEOGRAPHICAL POSITION
}

\author{
Evelina Hasa ${ }^{*}$, Sonila Duka, Ervis Lika, Sidita Mançe \\ "University of Tirana, Faculty of Natural Sciences, Chemistry Department, Tirana, Albania; \\ *Corresponding Author Evelina Hasa, e-mail: evelinahasa@gmail.com;
}

Received July 2020; Accepted August 2020; Published September 2020;

DOI: $\underline{\text { https://doi.org/10.31407/ijees10.405 }}$

\begin{abstract}
Essential oil percentage content of wild Salvia officinalis L. isolated with hydro distillation method was explored depending on geographical area. Chemical composition of essential oil collected in different areas of Albania located in North and South was assessed. The sampling was extended in 11 regions of Albania collected during the year 2017. Samples were collected on during summer in the wild. Hydrodistillation method has been applied for the extraction of essential oil in leaves. The oil was isolated in a Clevenger type apparatus and analysed with GC-FID and GC MS/MS QQQ. The samples were immersed in $500 \mathrm{ml}$ water and boiled using distillation flask heater for 3 hours, at boiling point temperature. The plant/liquid ratio used for this study was 1:10 (g:ml). The yield of essential oil in relation to the geographical position shows small changes from point to point. The percentage of essential oil level for the analyzed samples varies between $1.8-3.0 \%$. All eleven samples were used for oil profiling via GC-FID/GC MS analysis but only two of them, North and South region (Koplik/M2 and Dhembel/M10), were chosen in order to compare essential oil composition between north and south of Albania. Around 33 chemical compounds were analyzed and identified according to their relative retention time and mass spectra. The main components were $\alpha$-thujone (20-35\%), Camphor (18-44\%), 1,8-cineole (8-15\%).
\end{abstract}

Key words: essential oil, Salvia officinalis L, hydrodistillation, extraction, sampling, chromatographic 